\title{
Monostotic fibrous dysplasia of the spine: report of a case involving a cervical vertebra
}

\author{
D. Proschek $\cdot$ R. Orler $\cdot$ E. Stauffer $\cdot$ P. Heini
}

Received: 27 June 2003 / Published online: 27 September 2006

(C) Springer-Verlag 2006

\begin{abstract}
Monostotic fibrous dysplasia of the spine is a rare entity. Only 26 cases, of which 11 were located in the cervical spine, are to be found in the literature. We report a 56-year-old male patient with cervicobrachialgia of half year's duration. Radiographs showed a diffuse destruction of the vertebral body and the spinous process of $\mathrm{C}_{4}$. A biopsy of the spinous process confirmed histopathologically a fibrous dysplasia. Due to minor symptoms, no surgical treatment was performed or is planned unless in case of increasing pain, an acute instability or neurological symptoms.
\end{abstract}

Keywords Fibrous dysplasia $\cdot$ Monostotic $\cdot$ Spine $\cdot$ Cervical vertebra $\cdot$ Tumour

\section{Introduction}

In 1938, Dr. Lichtenstein evaluated a number of cases presenting with multiple osseous lesions, introducing the term of the polyostotic dysplasia to the medical community [9]. In later studies, especially in 1942, Lichtenstein and Jaffe reported about the affection of single or multiple bones [10].

Fibrous dysplasia is a benign affection of the skeleton consisting of one or more foci composed of cellular fibrous tissue containing irregular bone trabeculae

D. Proschek $\cdot$ R. Orler $\cdot$ P. Heini $(\bowtie)$

Department of Orthopaedic Surgery, Spine Service, Inselspital, University of Bern, 3010 Bern, Switzerland e-mail:paul.heini@insel.ch

E. Stauffer

Department of Pathology, Inselspital, University of Bern, Bern, Switzerland leading to a distortion and structural weakness of bone $[3,9,10,21]$. It is usually considered to arise from congenitally disturbed tissue development and may occur monostotic or polyostotic. Monostotic fibrous dysplasia can be found in every part of the skeleton, but predominantly in the jaw bones, ribs, femur and tibia [18]. Rarely, with about $1-5 \%$, fibrous dysplasia can be found in the spine $[3,4,21]$.

The following is a case report of a patient with monostotic fibrous dysplasia affecting the fourth cervical vertebra. Of the 26 cases reported in literature, only 11 patients (excluding our case) were documented with fibrous dysplasia of the cervical spine.

\section{Case report}

A 56-year-old male patient presented to us due to his cervicobrachialgia of half year's duration. At the time of examination there were moderate complaints of neck pain radiating to the right shoulder. The patient told about acute pain in his neck and right upper arm 6 months ago requiring morphine analgetics. Because of the regression of this acute pain, further evaluation was postponed and the patient resumed to work after a short interruption. Due to the ongoing pain he was referred for further evaluation. Clinical examination revealed no abnormal status except tenderness of the paravertebral muscles. The results of laboratory examinations and skin pigmentation showed no pathology.

Radiography of the spine showed a lytic and cystic destruction with diffuse expansion of the vertebral body and the spinous process of the fourth cervical vertebra (Fig. 1). CT scans and MR imaging confirmed the above-mentioned findings with no cortical destruction 
and no extraosseous, soft-tissue involving process (Fig. 2). Radiological findings suggested differential diagnosis including bone cysts, fibrous dysplasia, osteoblastoma, histiocytic fibroma, low-grade fibrosarcoma, enchondroma, metastases and chronic infection (Figs. 1, 2, 3).

Based on the radiological findings a biopsy of the spinous process was performed and confirmed histopathologically as fibrous dysplasia. Details showed a stroma, being rich in plump fibroblasts with formations of osteoid substance not assuming the aspects of osteoblasts. Bone trabeculae presented in a uniform and woven structure with no atypic cells or mitotic hyperactivity (Fig. 4).

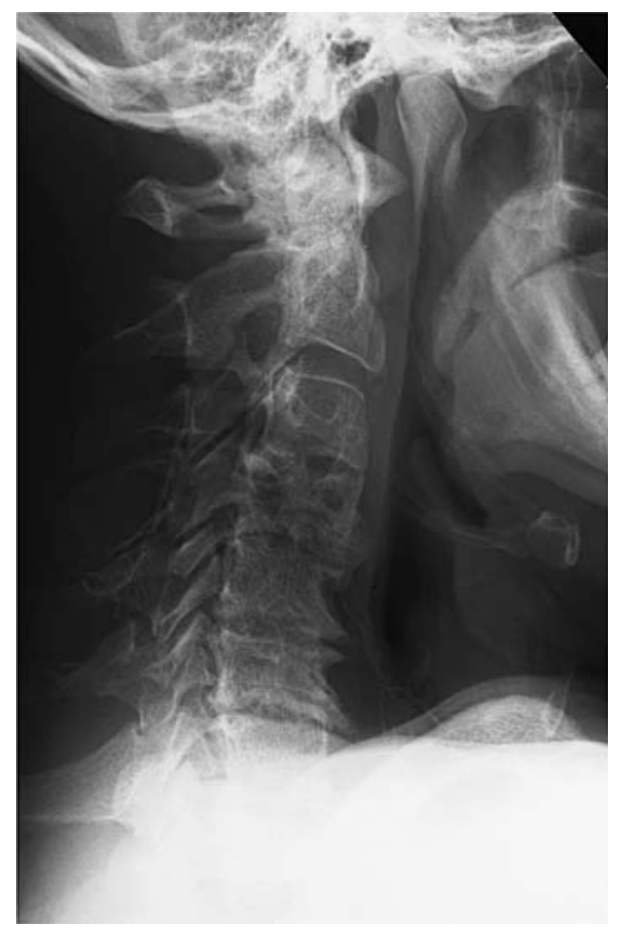

Fig. 1 Lateral view of the cervical spine, taken $x y$ weeks after onset of clinical symptoms. It shows an expansion and cystic degeneration of the fourth cervical vertebra. The severe degenerative changes only provoke minor symptoms
Clinical, radiological and especially the histopathological findings were those of fibrous dysplasia. Six months later, clinical examination again showed no abnormal status. The patient reported about only minor pain and radiological findings revealed a consolidation without progression of the fibrous dysplasia (Figs. 5, 6).

Due to minor symptoms no surgical treatment was performed or is planned unless in case of increasing pain, an acute instability or neurological symptoms.

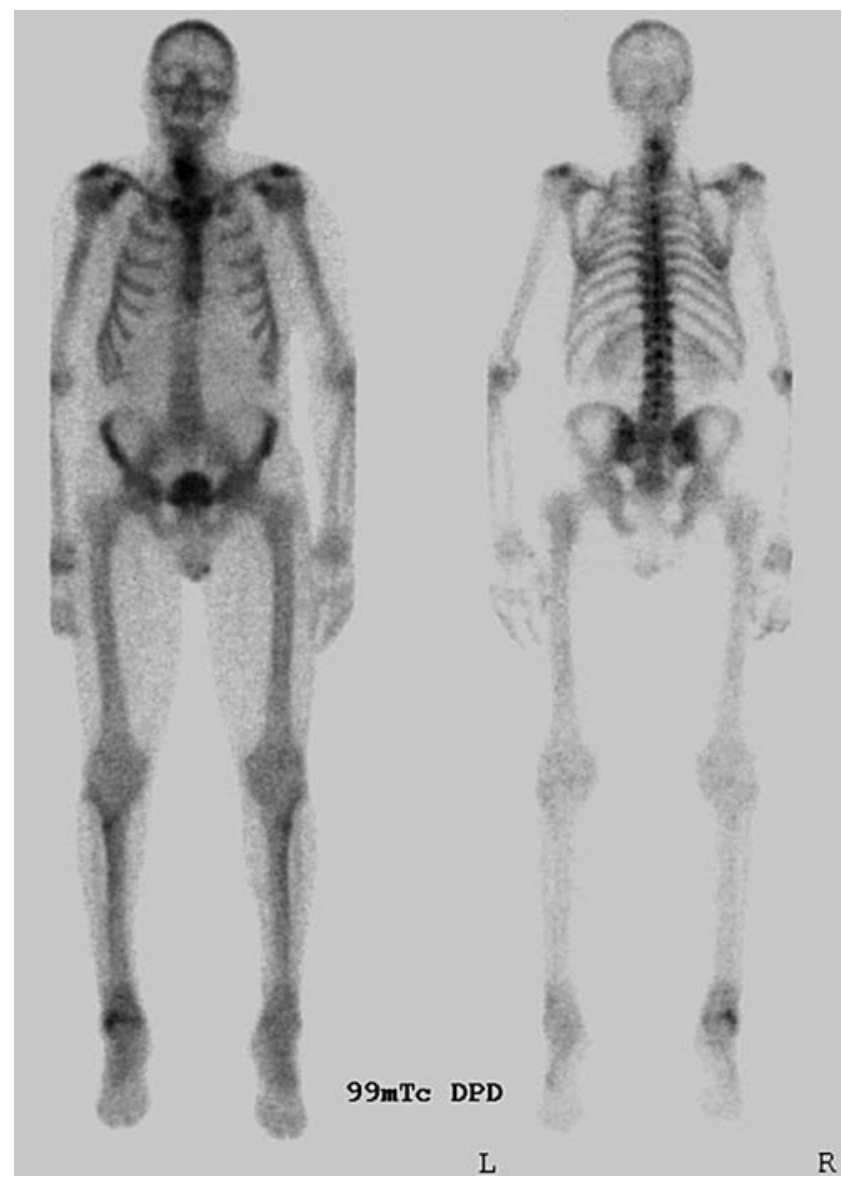

Fig. 3 Skeletal scintigraphy. Note the hot spots in the cervical part of the spine
Fig. 2 Axial computed tomography of the fourth cervical vertebra. A diffuse expansion as well as lytic and cystic degeneration with no cortical destruction is seen in the vertebral body, the pedicles, the lamina and the spinous process. No extraosseus/ soft-tissue transformations are spotted
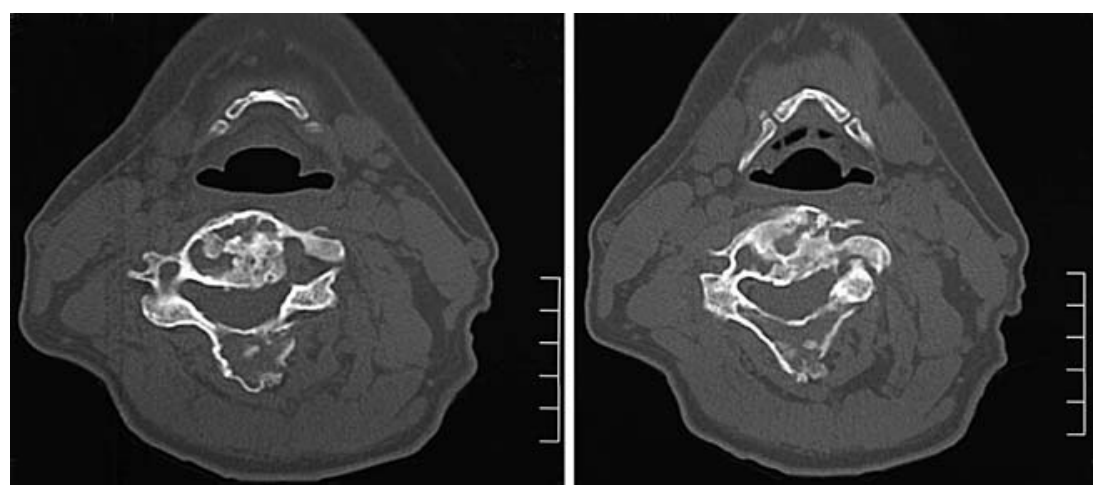

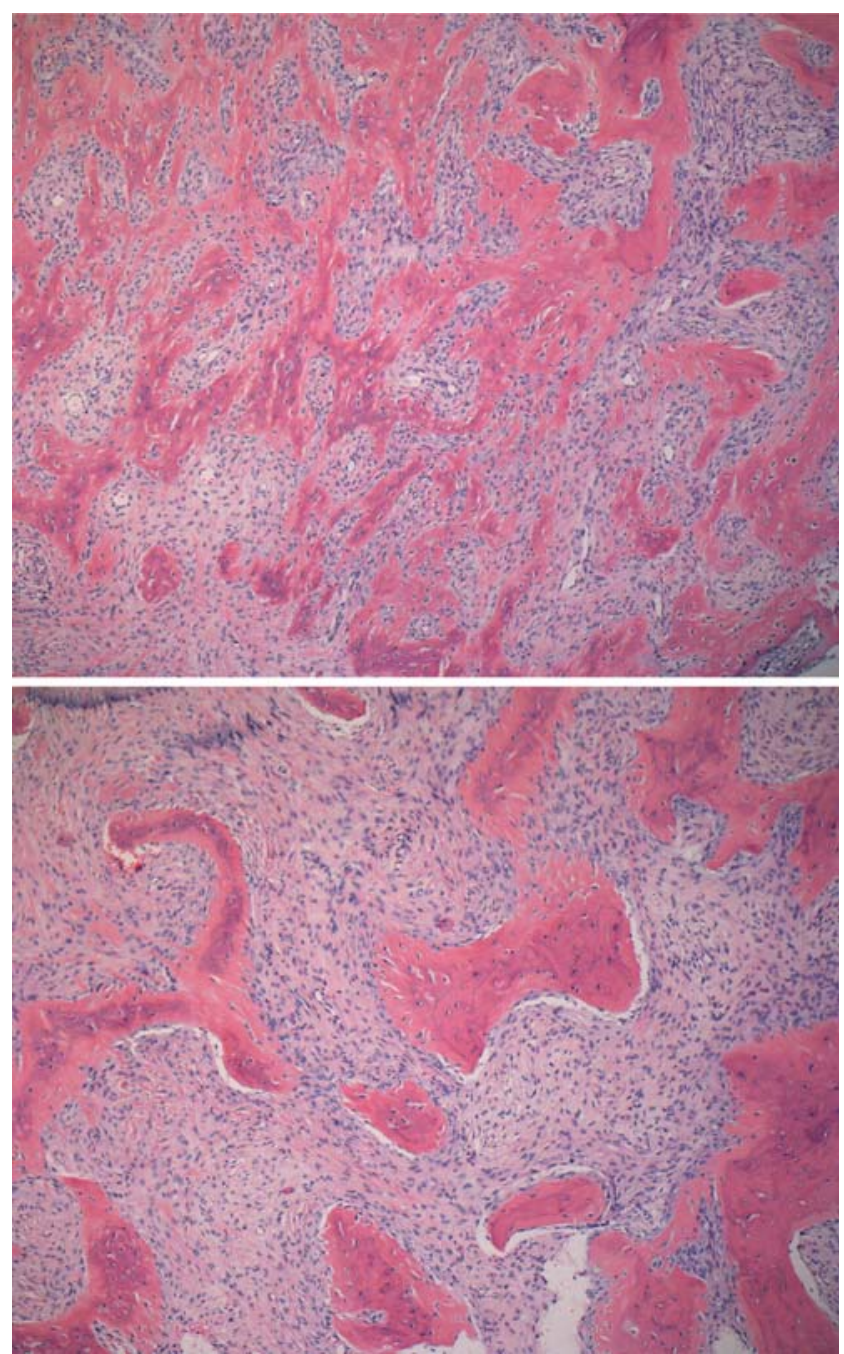

Fig. 4 Histological imaging of the biopsy taken from the fourth cervical vertebra. Bone trabeculae presented in a uniform and woven structure with many plump fibroblasts, few mitoses and no osteoblasts

\section{Discussion}

Fibrous dysplasia of the skeleton, congenital and similar to hamartomas, is an intraooseus neoformation of a fibrous tissue, which may be monostotic or polyostotic $[3,6,9,10]$. Medullary components are replaced by fibroplastic tissue. Skeletal lesions may be associated with skin pigmentation spots. Together with early skeletal maturity and (in females) precocious puberty, this association is known as Albright's syndrome [1, 11]. Other associations may be hyperthyroidism, diabetes mellitus, renal and cardiovascular anomalies. In agreement with its congenital nature, fibrous dysplasia begins during early childhood and is therefore relatively often recognised in younger age $[3,9,10]$. It accounts for about $5-7 \%$ of benign bone tumours. No

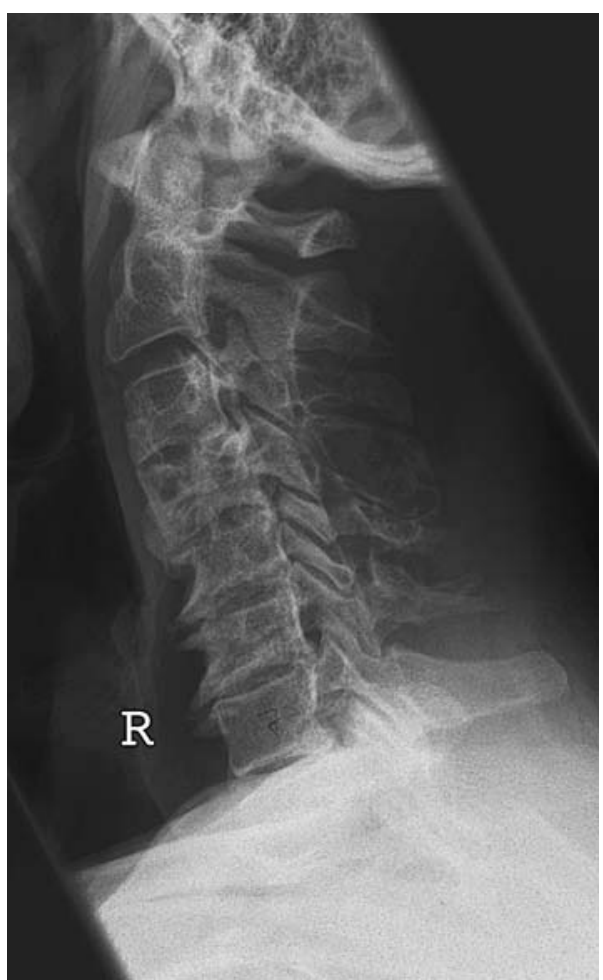

Fig. 5 Lateral view of the cervical region after 6 months still showing expansion and cystic degeneration of the fourth cervical vertebra. In comparison to the earlier radiological findings (Fig. 1) an organisation and consolidation of the fibrous dysplasia can be seen. The degenerative changes still provoke only minor symptoms

bone is immune to fibrous dysplasia. There is a predilection for the femur, tibia, maxillary bone, humerus, ribs and iliac bone [3]. After cessation of bone growth, fibrous dysplasia usually tends to be exhausted. A progression after having achieved adult age is a rare occurrence. However, passive progress is possible due to continuing degenerative changes in bone. The insurgence of a sarcoma on an area of fibrous dysplasia is a rare occurrence, and seems to be less than $1 \%$ of all cases $[3,8,18]$. Vertebral involvement in fibrous dysplasia is extremely rare, especially in monostotic variants of the cervical spine [2-4, 6, 14]. Table 1 gives a summary of the cases of fibrous dysplasia of the cervical spine found in literature. The 11 cases being reported separate into seven monostotic and four polyostotic variants.

The vertebral body is affected most frequently. However, the vertebral body has, in comparison to the other parts of the vertebra, the biggest amount of cancellous bone. Due to their close relationship to the vertebral body, involvement of the pedicles has been described in nearly all cases of body affection $[5,7,12$, $13,15-17,19-22]$. It could therefore be a possibility that fibrous dysplasia in the spine starts in the vertebral 


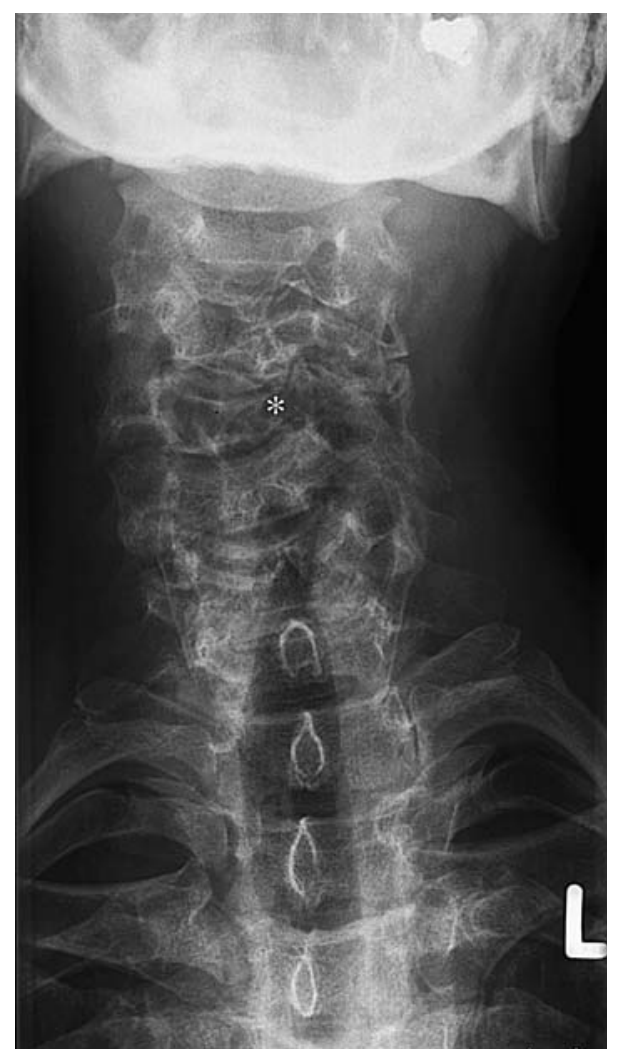

Fig. 6 An a.p. view of the cervical region after 6 months. C4 has collapsed on the left-hand side to a certain extend. (*) Compare Figs. 1 and 5

body and then continuously expands, via the pedicles, into the vertebral lamina and spinous process.

In the reported cases of fibrous dysplasia of the spine there is an expansion in nearly all parts of the vertebra (Table 1). Exceptions are found in older cases when only conventional X-rays were available for diagnosis. Therefore, it seems that fibrous dysplasia of the cervical spine does not affect only one part but the whole vertebra.

Constellation in the case presented here is the same with an affection of the vertebral body, the pedicles, the lamina and the spinous process of the fourth cervical vertebra.

Fibrous dysplasia usually starts in early childhood. After puberty, dysplastic areas rarely expand. In general, the progression of the skeletal lesions tends to be exhausted once adult age has been achieved. Therefore, cases with older patients getting symptomatic, especially those involving the spine, are rare. Only few cases of new foci of fibrous dysplasia in adult have been described [3]. It still remains unclear whether those new foci are de novo lesions or based upon secondary, degenerative changes in bones. However, adult patients usually are not getting symptomatic due to the fibrous dysplasia but the degenerative changes of the affected motion segment. Respecting the age of our patient, he is the oldest reported with having fibrous dysplasia of the cervical spine.

Diagnosis is difficult in adult patients. Main differential diagnosis includes metastatic lesions, bone cysts, enchondroma, histiocytic fibroma and malignant primary bone tumours. Clinical and radiological findings are often not specific for fibrous dysplasia. Tomography is important but cannot replace histopathology. The histological examination is essential. Stroma shows fibrous tissue with plump fibroblasts and forma-

Table 1 Reported cases of fibrous dysplasia of the cervical spine

\begin{tabular}{|c|c|c|c|c|c|}
\hline Cases & Age & Location & Symptoms & Treatment & Outcome \\
\hline Resnik et al. [17] & 27 & C6 (compl. vertebra) & Acute pain & Biopsy & NA \\
\hline Garfin et al. [22] & NA & C7 (body + pedicle) & Pain for years & $\begin{array}{l}\text { Arthrodesis } \\
\text { (C6-Th1) }\end{array}$ & Full recovery \\
\hline Wright et al. [21] & NA & $\begin{array}{l}\mathrm{C} 2+\mathrm{C} 5 \text { (body and } \\
\text { spinous process) }\end{array}$ & NA & NA & NA \\
\hline Stirrat et al. [20] & 25 & C2 (compl. vertebra) & Pain & $\begin{array}{l}\text { Iliac bone craft } \\
\text { (arthrodesis) }\end{array}$ & $\begin{array}{l}\text { Asymptomatic } \\
\text { for } 2 \text { years }\end{array}$ \\
\hline Smith et al. [19] & 47 & C4-C6 (ant. + post. elements) & Pain for months & $\begin{array}{l}\text { Partial corpectomy } \\
\text { C4-C6 }\end{array}$ & $\begin{array}{l}\text { Died postop. } \\
\text { (bronchopneumonia) }\end{array}$ \\
\hline Hu et al. [7] & 41 & C2 (compl. vertebra) & Mild pain & Arthrodesis $\mathrm{C} 1-\mathrm{C} 3$ & $\begin{array}{l}\text { Asymptomatic } \\
\text { for } 2.5 \text { years }\end{array}$ \\
\hline Ohki et al. [15] & 20 & C2 (spinous process) & $\begin{array}{l}\text { No pain, local expansion } \\
\text { of the tumour mass }\end{array}$ & Local excisions & $\begin{array}{l}\text { Asymptomatic } \\
\text { for } 5 \text { years }\end{array}$ \\
\hline Nishiura et al. [13] & 37 & C1-C3 (compl. vertebra) & $\begin{array}{l}\text { Pain, atlanto-axial } \\
\text { dislocation }\end{array}$ & $\begin{array}{l}\text { Ventral + dorsal } \\
\text { stabilisation }\end{array}$ & $\begin{array}{l}\text { Asymptomatic } \\
\text { for } 1 \text { year }\end{array}$ \\
\hline Ehara et al. [5] & 19 & C1 (lateral mass) & Asymptomatic & NA & NA \\
\hline Mezzadri et al. [12] & 35 & C5 (body + pedicle) & Spontaneous pain & C5-corpectomy & $\begin{array}{l}\text { Asymptomatic } \\
\text { for } 3 \text { years }\end{array}$ \\
\hline Perlick et al. [16] & 55 & $\begin{array}{l}\mathrm{C} 1+\mathrm{C} 2 \text { (spinous process, } \\
\text { body, pedicle) }\end{array}$ & Chronic pain & $\begin{array}{l}\text { Dorsal stabilisation } \\
\mathrm{C} 1+\mathrm{C} 2\end{array}$ & $\begin{array}{l}\text { Asymptomatic } \\
\text { for months }\end{array}$ \\
\hline
\end{tabular}


tions of osteoid substance not assuming the aspects of osteoblasts. Bone trabeculae are presented in a uniform and woven structure with no atypic cells or mitotic hyperactivity. These findings are typical and together with the examination allow finding the exact diagnosis. Difficulties sometimes arise in differentiating fibrous dysplasia from low-grade fibrosarcoma and low-grade osteosarcoma [3, 18]. Histopathologically, these low-grade tumours show more and especially atypic mitoses, and furthermore atypic fibro- and osteoblasts. Biopsy is unabdicable to isolate the abovementioned differential diagnosis and clear the way for exact diagnosis of fibrous dysplasia. Meanwhile genetic assessment allows for a definitive diagnosis by checking for the GS-alpha mutation.

Whether treatment of fibrous dysplasia in cervical spine is necessary is controversial $[5,7,12,13,15-17$, 19-22]. If there is a mechanical reason for the pain or even a compromise of neurological structures then a surgical intervention is indicated. Different ways are described, such as arthrodesis, laminectomy, corpectomy and local excisions. Due to different expansion of fibrous dysplasia there is no gold standard in operative treatment existent up to now. Each treatment should be oriented towards symptoms. A non-operative treatment can be followed as long as there are only minor complaints and no compromise of neurological structures.

The initial symptoms of our patient showed signs of instability. After 3 months, the vertebral body collapsed to a certain extent and regained stability (Fig. 6). After 9 months, the patient showed a consolidation in the clinical and radiological findings of the cervical vertebra. With having only minor complaints and no compromise of neurological structures operative treatment is not planned and not indicated at the moment.

\section{References}

1. Albright F, Butler AM, Hampton AO (1937) Syndrome characterized by osteitis fibrosa disseminata, areas of pigmentation and endocrine dysfunction. N Engl J Med 216:727-746
2. Avimadje AM, Goupille P, Zerback D, Begnard D (2000) Monostotic fibrous dysplasia of the lumbar spine. Joint Bone Spine 67(1):65-70

3. Campanacci M Bone and soft tissue tumors. Aulo Gaggi Editore Bologna and Springer, Berlin Heidelberg New York

4. Chow LTC, Griffith J, Chow WH (2000) Monostotic fibrous dysplasia of the spine: report of a case involving the lumbar transverse process and review of literature. Arch Orthop Trauma Surg 120:460-464

5. Ehara S, Kattapuram SV, Rosenberg AE (1992) Fibrous dysplasia of the spine. Spine 17:977-979

6. Henry A (1969) Monostotic fibrous dysplasia. J Bone Joint Surg 51B:300-306

7. Hu SS, Healey JH, Huvos AG (1990) Fibrous dysplasia of the second cervical vertebra. J Bone Joint Surg 72-A(5):781-783

8. Huvos AG, Higinbotham NL, Miller TR (1972) Bone sarcomas arising in fibrous dysplasia. J Bone Joint Surg Am 54:1047-1056

9. Lichtenstein L (1938) Polyostotic fibrous dysplasia. Arch Surg 36:874-898

10. Lichtenstein L, Jaffe HL (1942) Fibrous dysplasia of the bone: a condition affecting one, several or many bones, the graver cases of which may present abnormal pigmentation of skin, hyperthyroidism or still other skeletal abnormalities. Arch Pathol 33:777-816

11. McCune DJ, Bruch H (1937) Osteodystrophia fibrosa. Am J Dis Child 54:806-848

12. Mezzadri JJ, Acotto CG, Mautalen C (1999) Surgical treatment of cervical spine fibrous dysplasia: technical case report and review. Neurosurgery 44(6):1342-1349

13. Nishiura I, Koyama T, Takayama S (1992) Fibrous dysplasia of the cervical spine with atlanto-axial dislocation. Neurochirurgia 35(4):123-126

14. Oba M, Nakagami W, Maeda M, Kobayashi K (1998) Symptomatic monostotic fibrous dysplasia of the thoracic spine. Spine 23(6):741-743

15. Ohki I (1990) Monostotic fibrous dysplasia in the spine. J West Pacif Orthop Assoc 27:107-110

16. Perlick L, Rolf V, Wallny T, Schmitt O (2000) Die atlantoaxiale Instabilität als seltene Komplikation der fibrösen Dysplasie. Unfallchirurg 103:73-75

17. Resnik CS, Liniger JR (1984) Monostotic fibrous dysplasia of the cervical spine: case report. Radiology 151(1):49-50

18. Schajowicz F (1994) Tumor like lesions of the bone. Springer, Berlin Heidelberg New York, pp 567-581

19. Smith MD, Bohlman HH, Gideonse N (1990) Fibrous dysplasia of the cervical spine: a fatal complication of treatment. J Bone Joint Surg 72-A(8):1254-1258

20. Stirrat AN, Fisher CJ (1989) Fibrous dysplasia of the axis. Spine 14(2):243-245

21. Wright JF, Stoker DJ (1988) Fibrous dysplasia of the spine. Clin Radiol 39:523-527

22. Garfin WR, Rothman RH (1986) Case report 346. Skeletal Radiol 15:72-76 